\title{
Dependent Personality Disorder
}

National Cancer Institute

\section{Source}

National Cancer Institute. Dependent Personality Disorder. NCI Thesaurus. Code C92637.

A disorder characterized by an enduring pattern of an extreme need to be taken care of together with fear of separation that lead the individual to urgently seek out and submit to another person and allow that person to make decisions that impact all areas of the individual's life. 